\title{
Tradução
}

\section{A Idéia da Universidade: Processos de Aprendizagem*}

\author{
Jurgen Habermas
}

\section{á}

No primeiro número do primeiro volume da revista "D/c Wandlung" (A Mudança), fundada por Karl Jaspers c Alfred Weber, Dolf Stcrnberger c Alexander Mitschcrlich, pode ler-sc o discurso pronunciado pelo filósofo, regressado da "emigração interior" à sua cátedra, na reabertura da Universidade de Heidelberg cm 1945: Karl Jaspers. 'Vi Renovação da Universidade". Com a ênfase do recomeço suscitada pela situação histórica do momento, Jaspers retoma então a idéia central do seu escrito sôbre 'VI Idéia da Universidade", publicado cm 1923 c reeditado em 1946. Quinze anos mais tarde, cm 1961, o livro reapareceu numa nova versão.

Jaspers continua a partir candidamente de premissas que radicam na sociologia implícita do idealismo alemão. De acordo com elas, as estruturas institucionais são formações do espírito objectivo. Uma instituição só manterá a sua funcionalidade na medida cm que seja capaz de encarnar de forma viva a idéia que lhe é inerente. Logo que o espírito abandona, uma instituição cristaliza $\mathrm{cm}$ qualquer coisa de meramente mecânico, do mesmo modo que o organismo desanimizado se desintegra em matéria morta.

Também a universidade deixa de constituir uma totalidade a partir do momento $\mathrm{cm}$ que os laços que consolidam a sua consciência corporativa

\footnotetext{
* Texto de uma conferência proferida no Instituto Alemão, no dia 30-03-87, cm Lisboa. Agradece-se BO Prof. Jurgen Habermas a autorização Je publicação e ao Instituto Alemão de Lisboa as facilidades concedidas.

Noia do Editor: Publicado originalmente na Revista di Educação, Lisboa, Portugal, vcl 2, p-3-9,1987. Republicado aqui com a permissão da citada revista, mantidas as peculiaridades lingüisticas da tradução portuguesa.
} 
se desintegram. As funções que a universidade desempenha para a sociedade permaneceriam assim ligadas, como que a partir de dentro, com os Objectivos, os motivos e as acções dos membros que nela colaboram $\mathrm{cm}$ regime de divisáo de tarefas, ao nível de uma rede de intenções comuns. Neste sentido, a universidade deve representar enquanto instituição, c cimentar enquanto centro motivador, uma forma de vida intersubjcctivamcntc partilhada pelos seus membros, com um estatuto que se pode dizer exemplar. Aquilo que desde Humboldt dá pelo nome de "Idéia da Universidade" é o projecto de materialização de uma forma de vida ideal. Esta idéia distinguir-se-á ainda de outras idéias fundadoras pelo facto de não remeter apenas para uma das muitas formas de vida particulares dos começos da sociedade burguesa, estratifícada $\mathrm{cm}$ corporações profissionais, mas antes - mercê das suas afinidades com a ciência e a verdade - para uma instância universal anterior ao pluralismo das formas de vida sociais. A idéia da universidade remete para os princípios culturais segundo os quais se constituem todas as configurações do espírito objectivo.

Mesmo abstraindo desta excessiva pretensão de exemplaridade, não será já de si irrealista a premissa que pretende que uma estrutura inabarcávcl c incontrolávcl como o sistema universitário moderno deve estar perpassada c ser sustentada pela forma de pensar comum de todos os seus membros? "Só quem traz cm si a idéia da universidade pode pensar c agir de forma adequada em prol da universidade": não deveria Jaspers ter já aprendido com Max Weber que a realidade organizacional, na quai se sedimentam os sistemas parciais funcionalmente especificados de uma sociedade altamente diferenciada, assenta sôbre premissas completamente diferentes? A capacidade funcional de tais organizações e instituições depende precisamente do facto de os motivos dos seus membros estarem desligados dos Objectivos c das funções da organização. As organizações já não incarnarli idéias. Pretender vinculá-las a idéias significa limitar o seu âmbito operativo ao horizonte relativamente estreito do mundo da vida (Lebensweit) intersubjectivamente partilhado pelo seus membros. Um dos muitos artigos com que o jornal Frankfurter Allgemeine Zeitung (FAZ) homenageou a Universidade de Heidelberg pelo seu sexto centenário 
chega também a esta conclusão bem sóbria: "A profissão de fé em Humboldt é a mentira vital das nossas universidades, pois elas não têm qualquer idéia". De um ponto de vista como este, todos os reformadores universitários que, como Jaspers, apelaram (e, num tom que vai enfraquecendo, ainda apelam) para a idéia da universidade, se incluem entre aqueles espíritos que, numa atitude meramente defensiva, fazem uma crítica civilizacional hostil à modernização.

Jaspers não estava, pois, livre dos traços idealistas de um pessimismo civilizacional estranho à sociologia e culturalmente elitista, que o mesmo é dizer da ideologia de fundo dos mandarins alemães. Mas não foi o único, nem sequer o mais influente entre aqueles que, nos anos sessenta, clamaram pela permanência de uma reforma da universidade retomando as idéias dos reformadores prussianos. Em 1963, dois anos depois da nova versão do escrito de Jaspers, entrava cm cena Helmut Schelsky, com um livro de marca inconfundível já no próprio título: "Solidão e Liberdade". E dois anos mais tarde aparece a versão final de um memorando (primeiramente apresentado cm 1961) da Liga dos Estudantes Socialistas Alemães (SDS) com o título "A Universidade na Democracia". Três escritos reformadores provenientes de três gerações e de três perspectivas diferentes. Eles assinalam uma distância cada vez maior $\mathrm{cm}$ relação a Humboldt - e uma crescente sobriedade de marca sociológica em relação à idéia da universidade. Apesar da distância entre gerações e da mudança de mentalidades entretanto verificada, nenhum destes três intervenientes abandonou a perspectiva de uma renovação crítica precisamente daquela idéia.

Vinte anos e uma reforma organizativa da universidade, tíbia e em parte renegada, nos separam hoje destas tentativas de encontrar uma nova forma para a universidade à luz da sua idéia renovada. Que aprendemos nós com estes vinte anos? Tudo parece indicar que quem tinha razão eram aqueles realistas que, como nota Jaspers, logo a seguir à Primeira Guerra proclamavam: "A idéia da universidade está morta! Deixemo-nos de ilusões e de perseguir fantasmas!" Ou será que não entendemos 
correctamente o papel que uma tal idéia poderia continuar a desempenhar na fomiação de uma consciência própria dos processos de aprendizagem a nível universitário? Teria a universidade que deixar, cair, como um invólucro vazio, nessa sua caminhada para a especialização funcional adentro de um sistema científico em diferenciação acelerada, aquilo a que cm tempos chamara a sua idéia? Ou será que a forma universitária dos processos de aprendizagem científica organizados depende, ainda hoje, de umfeixe convergente de funções que não exige necessariamente um modelo dominante mas, com certeza, uma certa comunhão na imagem que de si projectam os membros da universidade - que o mesmo é dizer um resto de consciência corporativa?

Por via deste curioso feixe de funções, as universidades estão ainda enraizadas no "mundo da vida". No entanto, os fenômenos gerais de socialização, da transmissão de saberes c da formação de uma vontade de integração social, através dos quais o "mundo da vida" se reproduz, continuam-se no interior da universidade apenas sob as condições, altamente artificiais, de um processo de aprendizagem científica programado para a obtenção de conhecimentos Objectivos. Enquanto esta unidade de funções se não desagregar completamente, a idéia da universidade não estará totalmente morta. É preciso não subestimar a complexidade $\mathrm{c}$ a diferenciação interna deste complexo coeso. Na hora do nascimento da universidade clássica alemã, os reformadores prussianos conceberam-na à luz de uma imagem que sugere desde logo uma relação ainda muito simplificada, entre os processos de aprendizagem científica e as formas de vida das sociedades modernas. O que cies fizeram, a partir da sua perspectiva de uma filosofia idealista da reconciliação, foi atribuir à universidade uma força de totalização que desde logo se revelaria ser uma exigência a que esta instituição não podia corresponder. Foi cm grande parte a este impulso que a idéia de universidade na Alemanha ficou a dever o seu fascínio - até aos anos sessenta do nosso século.

Para clarificar a complexidade das articulações entre a universidade e o "mundo da vida", proponho-me libertar o cerne da idéia da universidade de uma série de "cascas" que o envolvem e que foram simplificando 
excessivamente aquela idéia. Começo por retomar a idéia clássica de Schelling, Humboldt e Schleiermacher, para depois me debruçar sobre as três variantes da sua renovação, com Jaspers, Schelsk e os reformadores do SDS.

Humboldt c Schleiermacher associam à idéia de universidade dois pensamentos centrais. Em primeiro lugar preocupa-os o problema das possibilidades de institucionalização da ciência moderna, liberta das tutelas da religião c da Igreja, de modo a que a sua autonomia não seja posta em perigo por outras instâncias - quer elas sejam as imposições da autoridade do Estado, que possibilita a existência exterior da ciência, quer se trate das pressões da sociedade burguesa, interessada nos resultados úteis do trabalho científico. Humboldt c Schleiermacher vêem a solução do problema numa autonomia científica com organização estatal, que protegeria as instituições científicas contra as intervenções políticas e contra os imperativos sociais. Por outro lado, interessa-lhes explicar também porque razão é do próprio interesse do Estado garantir à universidade essa imagem exterior de uma liberdade ilimitada no seu interior. A idéia de um tal "Estado de cultura" recomendar-se-ia pelas próprias consequiências benéficas que derivariam da força unificadora c totalizante de uma ciência institucionalizada sob a forma da investigação. Basta que o trabalho científico se entregue à dinâmica interna dos processos de investigação: assim - disso estavam ambos convencidos - a cultura moral c toda a vida espiritual da nação convergiriam nas instituições científicas superiores como num foco.

Estas duas idéias fundem-sc na ideia da universidade e explicam algumas das mais óbvias características da tradição universitária alemã. Permitem, cm primeiro lugar, compreender a relação afirmativa com o Estado por parte de uma ciência universitária que se apresenta como apolítica; $\mathrm{cm}$ segundo lugar, a atitude defensiva da universidade para com a praxis no plano profissional, particularmente em relação às exigências de uma função formativa, que poderia pôr em risco o princípio da unidade 
de ensino e investigação; e, em terceiro lugar, a posição central das faculdades de ciências humanas no âmbito da universidade, bem como a ênfase posta na importância da ciência para a cultura c a sociedade em geral. Da idéia da universidade resulta, portanto, de um lado, a acentuação da idéia - muito susceptível de desenvolvimento posteriores, porque remete para a especificidade funcional do sistema científico - da autonomia da ciência (uma autonomia que deve ser entendida apenas na "Solidão e Liberdade" da distância em relação à sociedade burguesa e ao espaço público político); do outro lado, a força universal e culturalmente determinante de uma ciência que concentraria em si, reflexivamente, a totalidade do "mundo da vida".

Os reformadores da altura podiam conceber o processo científico como um processo circular de ensino $\mathrm{c}$ investigação narcisisticamente fechado, uma vez que a filosofia do idealismo alemão, $\mathrm{cm}$ si mesma, exigia a unidade de ensino e investigação. Enquanto que hoje separamos a discussão sobre o estudo actual da investigação da exposição desse nivel do conhecimento no âmbito do ensino, Schelling mostra, nas suas "Lições sobre o Método do Estudo Acadêmico", que a construção do pensamento filosófico gera a forma da sua transmissão pedagógica: esta concepção de teoria exigia, assim, um processo de construção estruturante que coincidia com a sua exposição curricular.

De forma semelhante se entendia que a universidade devia a sua ligação interna com o "mundo da vida" à força totalizante da ciência. Estes reformadores atribuíam à filosofia uma força unificadora com referência a três aspectos a que hoje chamaríamos tradição cultural, socialização e integração social. A ciência filosófica fundamental era, em primeiro lugar, de base enciclopédica e estava por isso $\mathrm{cm}$ condições de assegurar a unidade na diversidade das disciplinas científicas, bem como a unidade da ciência com a arte e a crítica, por um lado, e o direito e a moral, por outro lado. A filosofia apresentava-se como a forma de reflexão da cultura no seu todo. Em segundo lugar, o seu fundo platonista asseguraria a unidade dos processos de investigação e dos processos de formação humana. Pensava-se, de facto, que as idéias, ao serem apreendidas, se tornam simultaneamente constitutivas do caracter ético 
do sujeito dc conhecimento, libertando-o assim de toda a unilateralidade. A elevação ao absoluto abre caminho para o desenvolvimento universal e pleno da individualidade. Como o convívio com este tipo de ciência é um factor dc razão, "os viveiros da ciência podem também ser instituições de cultura geral". Finalmente, o fundamento de reflexão filosofica de toda a construção teórica prometia a unidade de ciência e esclarecimento crítico (Aufklarung). Enquanto que hoje a filosofia se transformou numa disciplina que atrai o interesse esotérico dc especialistas, uma filosofia que se fundamentava na relação do sujeito de conhecimento consigo próprio e desenvolvia todos os conteúdos de conhecimento por via de uma dinâmica reflexiva dc pensar, estava $\mathrm{cm}$ condições dc satisfazer, simultaneamente, o interesse esotérico do especialista pela ciência c o interesse exotérico do leigo no conhecimento de si e no esclarecimento crítico. Aprendendo o seu tempo na idéia, a filosofia, dirá mais tarde Hegel, deve substituir a força socialmente integradora da religião pela força reconciliadora da razão. Por isso, Fichte pôde já ver na universidade, que se limita ainda a institucionalizar uma ciência deste teor, o berço de uma sociedade emancipada futura, c mesmo umfonun de formação nacional. Uma ciência que assim propicia o exercício da reflexão leva à clarificação, não das coisas que nos permanecem estranhas, mas sim das raízes mais profundas da nossa própria vida.

O risco c o caracter inverossímil da idéia de universidade que nos surge naqueles célebres documentos de fundação só se manifestam em toda a sua extensão quando pensamos nas condições exigidas para a institucionalização de uma tal ciência - uma ciência que, como se viu, possibilitaria c garantiria, apenas através de sua estrutura interna, a unidade de ensino e investigação, a unidade das ciências c da cultura geral e ainda a unidade de ciência e esclarecimento crítico (Aufklarung).

$A$ unidade de investigação e ensino, entendida no seu sentido mais específico, significa que só se ensina e se aprende à medida das necessidades do processo inovador do progresso científico. A ciência deve também poder reproduzir-se a si própria, significando isto que os professores devem formar a sua própria descendência científica. O futuro investigador é o único objectivo em função do quai a universidade dos sábios investigadores assume tarefas formativas. Apesar dc tudo, esta limitação da formação 
profissional na universidade à preparação de novas gerações de cientistas, manteve uma certa plausibilidade, pelo menos para as faculdades de ciências humanas, enquanto o corpo de professores era complementado a partir do círculo dos professores liceais por eles formados.

Por outro lado, a idéia da unidade das ciências só poderia afirmarse se as faculdades superiores se submetessem à liderança científica de uma faculdade de artistas totalmente transformada, e se a filosofia, que aí tinha o seu lugar, avançasse realmente para a posição de ciência fundamental de uma liga das ciências da natureza e do espírito. É este o sentido da polemica contra as ciências utilitárias (ou ciências "ganha-pão"), contra a dispersão $\mathrm{cm}$ escolas especializadas, contra o caracter meramente derivado daquelas faculdades "que encontram a sua unidade, não directamcntc no conhecimento, mas numa actividade da vida exterior". A conseqüência necessária destas posições, desde logo imposta à revelia dos factos, foi a da reivindicação da hegemonia das faculdades de filosofia, "uma vez que todos os membros da universidade, sem distinção de faculdades, nelas têm de encontrar as suas raízes" (Schleiennacher).

A unidade de ciência e cultura geral tinha como pressuposto institucional a unidade de mestres c discípulos: "A relação professor-aluno mudou completamente: não é o primeiro que serve o segundo, ambos servem a ciência". Esta relação de tipo complementar, fundada na cooperação e essencialmente igualitária, haveria de ganhar corpo nas modalidades de funcionamento dos seminários. E era incompatível com a estrutura personalizada que, em breve, se delinearia nos institutos hierarquicamente organizados, para uma investigação orientada pelo modelo das ciências naturais experimentais.

Foi, finalmente, empolada um tanto a idéia da unidade entre a ciência e o esclarecimento crítico (Aufklàrung), a partir do momento $\mathrm{cm}$ que se sobrecarregou a autonomia da ciência com a expectativa de que a universidade pudesse, intramuros e como que numa espécie de microcosmos, antecipar uma sociedade de homens livres e iguais. A ciência filosófica parecia concentrar de tal modo em si as competências gerais da espécie que, da perspectiva de Humboldt, as instituições científicas superiores 
constituíam, não apenas o topo de todo o sistema educativo, mas também a "cúpula da cultura moral da nação". O certo é que desde o princípio não ficou claro como iria conciliar-se a missão crítico-emancipatória com a abstinência política, que era afinal o preço que a universidade tinha de pagar pela organização estatal da sua liberdade. Estes pressupostos institucionais para a implementação da ideia fundadora da universidade alemã, ou nunca estiveram verdadeiramente presentes, ou se revelaram, ao longo do século XIX, cada vez menos concretizáveis na prática. Um sistema diferenciado de actividades exigia desde logo a preparação científica para cada vez mais profissões acadêmicas. A longo prazo, as escolas técnicas superiores, as escolas comerciais, as escolas superiores de pedagogia, as escolas de belas-artes, não podiam manter-se à margem da universidade. Depois, as ciências empíricas, nascidas no seio das faculdades de filosofia, passaram a seguir um ideal de racionalidade metodológica que condenava ao fracasso qualquer tentativa de integração enciclopédica dos seus conteúdos numa hermenêutica filosófica global. Esta emancipação das ciências empíricas marcou a decadência das interpretações monistas c metafísicas do mundo, c, no meio de um pluralismo de forças ideológicas, a filosofia perdeu também o seu monopólio como base interpretativa da cultura $\mathrm{cm}$ geral. Em terceiro lugar, a ciência ganhou terreno como força produtiva importante da sociedade industrializada. Pensando no Instituto Liebig em Gieben, o governo do Estado de Baden acentuava, por exemplo "a importância da química para a agricultura", já cm 1850. As ciências da natureza perderam parte da sua função de suporte de uma imagem do mundo a favor da produção de saber tecnicamente aplicável. As condições de trabalho da investigação organizada $\mathrm{cm}$ institutos favoreciam mais os imperativos funcionais da economia c da administração do que os da cultura geral. Por fim, a formação acadêmica serviu na Alemanha de factor de demarcação social para uma camada da burguesia culta, orientada pelo modelo do funcionário superior. Esta consolidação da diferenciação profissional entre formação escolar geral e formação acadêmica veio, porém, reafirmar estruturas de classe que desmentiam definitivamente o 
conteúdo universalista da idéia da universidade e as promessas de emancipação social global a ela associadas.

Quanto mais estas contra-correntes eram consciencializadas, tanto mais a idéia da universidade tinha de se afirmar contra os factos - e acabou por degenerar em ideologia de uma camada profissional com elevado prestígio social. No que diz respeito às ciências sociais e humanas, Fritz K. Ringer situa a decadência da cultura dos madarins alemães no período entre 1890 e 1933. Na esfera de uma interioridade protegida pelo poder, que era a desses mandarins, o ideal cultural neo-humanista transformou-se na consciência, perpassada pela ideia de uma aristocracia do espírito, apolítica e acomodatícia, própria de uma Escola toda voltada para a investigação, distante da praxis c endogenamente autônoma. É claro que também temos de ver o lado positivo. A idéia da universidade contribuiu, nas suas duas formas - enquanto idéia c enquanto ideologia - para o esplendor e o êxito internacional incomparável da universidade alemã e da sua ciência durante o século XIX e até aos anos trinta do nosso século. Com a sua organização estatal da autonomia científica, ela transferiu a diferenciação das disciplinas científicas para a dinâmica interna, livre dos próprios processos de investigação. A Sombra de um humanismo cultural só superficialmente absorvido, as ciências da natureza ganharam rapidamente a sua autonomia e transformaram-se, com o seu trabalho de investigação organizado em institutos, num modelo que deu frutos também no plano das ciências sociais c humanas funcionando $\mathrm{cm}$ regime de seminários, isto apesar de todo o peso do seu espírito positivista. Ao mesmo tempo, a ideologia dos mandarins alemães proporcionou à universidade uma forte consciência de si enquanto corpo, programas de apoio por parte das instâncias culturais do Estado e uma posição socialmente reconhecida. E — "last but not least" — o excedente utópico inerente à idéia de universidade permitiu manter ainda um potencial crítico que convergia com as convicções, a um tempo universalistas o individualistas, do racionalismo ocidental $-\mathrm{c}$ que, de tempos a tempos, pôde ser reanimado com vista a uma renovação da instituição. 
Era assim, de qualquer modo, que pensavam os reformados nos começos da década de sessenta. Depois de 1945, o primeiro impulso para a renovação tinha sido insuficiente. Para além de um esgotamento em termos materiais, tinha-se esgotado nessa altura também a consciência corporativa. A idéia da universidade, na sua forma tradicional da ideologia dos mandarins, tinha sobrevivido também ao nazismo. Mas, pela sua comprovada impotência contra o regime nazi ou mesmo pela cumplicidade com ele, provou-se aos olhos de toda a gente que ela era uma idéia sem substância. Apesar de tudo, depois de 1945, os apaniguados tradicionalistas da idéia humboldtiana tiveram mesmo na defensiva, força suficiente para retardar tentativas de reforma bem intencionadas, c para se entenderem com os pragmatistas do Conselho para a Ciência, fundado no fim dos anos 50. O inevitável crescimento quantitativo das universidades processou-se então como uma expansão adentro de estruturas inalteradas.

E numa situação como esta que Jaspers regressa a Humboldt e que Sehelsky c os estudantes do SDS tentam uma apropriação crítica da mesma herança, munidos de um instrumentário sociológico que lhes permite uma maior distanciação, c que explica o facto de fazerem anteceder as suas propostas de reforma de um sóbrio diagnóstico das mudanças estruturais entretanto verificadas na universidade. Como fundo, reconhecem-se já as comparações, a nivel internacional, dos sociólogos da cultura, as análises econômicas do mercado de trabalho, os postulados cívicos dos responsáveis pela política cultural c educativa. Tudo isto é sintetizado por Schelsky na sua fórmula dos "postulados Objectivos". É que estes processos têm um caracter sistêmico c geram estruturas que se autonomizam em relação ao "mundo da vida": esvaziam a consciência corporativa da universidade c destroem aquelas ficções de unidade que Humboldt, Schleiermacher e Schelling pretendiam fundamentar com a força totalizante da reflexão científica. O curioso é que nem Schelsky nem os reformadores de esquerda se decidem por uma mera adaptação das universidades aos postulados Objectivos do momento: eles não apostam no tipo de reforma tecnocrática permanente, que entretanto começava 
realmente a dominar a cena. Num autor como Schelsky, a sua teoria da tecnocracia, desenvolvida na altura, deixaria mesmo esperar uma opção desse tipo. Em vez disso, porém, Schelsky retoma as idéias de Humboldt c apela para a necessidade de "dar forma" (gesíalten) a esses postulados Objectivos: "O facto essencial é que estas tendências objectivas do desenvolvimento são unilaterais... e que por isso devem ser activadas, tanto numa ligação à tradição, como por forças estruturantes de sinal contrário, que não são óbvias, c a que só pode chegar através de um grande esforço criativo". Insiste-se $\mathrm{cm}$ que o sistema científico diferenciado não deve desenvolver-se apenas $\mathrm{cm}$ ligação com a economia, a técnica $\mathrm{c}$ a administração, mas antes, por meio da sua tradicional convergência de funções, manter-se enraizado no "mundo da vida". E uma vez mais esse feixe convergente de funções deve encontrar a sua legitimação na própria estrutura da ciência.

As iniciativas de reforma de maior exigência teórica nos começos da década de 60 voltam, como se vê, a partir de uma idéia de ciência a que se pode ainda atribuir uma qualquer força unificadora; c uma vez mais a universidade é entendida apenas como a sua forma exterior c organizativa. É claro que a posição relativa da filosofia perante as ciências se tinha entretanto alterado de tal modo que ela deixara de ser o centro das ciências especializadas e diferenciadas. Mas quem iria ocupar o lugar deixado vago? E seria mesmo necessário continuar agarrado à idéia da unidade das ciências? A força totalizante do processo científico não podia com certeza continuar a ser pensada como síntese, nem hipostasiada com recurso a uma relação objectal de tipo metafísico com o absoluto ou com a totalidade do mundo. Uma teoria que arriscasse o recurso a uma totalidade directamente ou no percurso através das ciências específicas - era agora inconcebível.

A resposta de Jaspers é relativamente convencional. Concede que a racionalidade das ciências empíricas, de Objectivos abertos c determinadas apenas pelo método, é meramente processual e não pode já fundamentar uma unidade de conteúdo num cânone de disciplinas que se vão diferenciando de forma inprevisível; mas, à filosofia, que começou por ser empurrada para a periferia e depois se viu confinada às tarefas do 
esclarecimento da situação existencial c da análise de uma globalidade não objectivável, estará destinado no escrito de Jaspers ainda um papel especial frente às disciplinas libertas. As ciências precisarão até da liderança da filosofia, porque só ela é garante do motivo da vontade absoluta de saber e do hábito das formas de pensamento científico pela reflexão, c só ela poderia assegurar o pressuposto c a certeza das idéias condutoras de uma investigação.

Menos idealistas são as considerações de Schelsky, que substitui a filosofia por uma teoria das ciências. Parte de uma tripartição do cânone de disciplinas $\mathrm{cm}$ ciências da natureza, sociais e humanas. As disciplinas desenvolvem-se de forma autônoma, mas aqueles três grupos estão, nas suas formas de saber específicas, funcionalmente articulados de forma diferente com a sociedade moderna. Não podem já ser abarcados na sua totalidade pela reflexão filosófica; o que acontece é que a filosofia "emigra" para as várias ciências c aninha-se nelas como uma forma de auto-reflexão de uma dada disciplina. Nasce assim um equivalente para as unidades da universidade humboldtiana, entretanto fictícias: "Derivando das ciências especificas" c transcendendo-as criticamente na medida $\mathrm{cm}$ que as transforma $\mathrm{cm}$ seu objecto, a filosofia volta a apoderar-se indirectamente da totalidade da civilização científica como seu objecto. Analisando os limites c as condições de cada ciência particular, ela confere-lhe uma abertura face ao estrangulamento das suas "relações com o mundo".

Eu próprio me assumi, pela mesma altura, como paladino de uma crítica material da ciência, cuja função era a de esclarecer a articulação entre fundamentos metodológicos, pressupostos globais de fundo c contextos Objectivos de aplicação prática. Eu tinha, como Schelsky, a esperança de que, a este nível de auto-reflexão crítico-cientifíca, se pudessem clarificar, a partir de si próprias, as relações dos processos de investigação com o "mundo da vida" - e não apenas as relações com os processos de aplicação prática da informação científica, mas sobretudo as relações com a totalidade cultural, como os processos gerais de socialização, a continuidade das tradições c o esclarecimento político do espaço público. 
Há ainda um outro elemento da herança humboldtiana que renasceu com estas iniciativas para uma reforma. Refiro-me ao significado exemplar atribuído à autonomia da ciência, independentemente da garantia constitucional da liberdade de ensino e investigação. Jaspers entendia por autonomia científica a concretização de uma rede comunicativa a nivel internacional, que protegeria os Estados livres dos totalitários. Schelsky empresta a esse conceito uma nota personalista-existencial: autonomia científica seria a distanciação, exercida na solidão do dever, c a atitude eticamente soberana, em relação a coerções práticas como as reificações de ordem sistêmica que resultavam das deficiências estruturantes dos postulados Objectivos da sociedade moderna. E para os autores do memorando do SDS, como $\mathrm{cm}$ geral para os reformadores de esquerda, associava-se àquilo que na altura defendíamos como democratização da universidade, não exatamente a transposição para a universidade de modelos institucionais de formação de uma vontade política, não a constituição de um Estado dentro do Estado, mas com certeza a expectativa de uma capacidade de acção política exemplarmente entendida como uma forma de auto-gestão participada.

Numa adenda ao seu livro, Schelsky explica $\mathrm{cm} 1970$ o fracasso das reformas pelo facto de o sistema científico se ter diferenciado em alto grau sob a pressão de uma complexidade cada vez maior, e por isso "não pode ser sustentado, nas suas diversas funções, por um modelo referencial (Leitbild) aglutinador". A expressão "modelo referencial" denuncia certas premissas que talvez fossem demasiado ingênuas para poderem acompanhar a dinâmica diferenciadora da investigação. Irrealista era claramente a suposição de que seria possível implantar no seio de uma investigação organizada $\mathrm{cm}$ disciplinas uma forma de reflexão que não emergisse da própria lógica da investigação científica. A história das ciências empíricas modernas ensina-nos que a "normal science" se caracteriza por práticas de rotina e por um objectivismo que protege o dia-a-dia da investigação de possíveis problematizações. Os impulsos para a reflexão são desencadeados por crises, mas mesmo nessas alturas a rejeição de paradigmas em degenerescência $\mathrm{cm}$ favor de novos paradigmas faz-se normalmente de forma espontânea. Nos casos, porém, $\mathrm{cm}$ que se verifica uma prática contínua de reflexão sobre os fundamentos 
c de crítica da ciência, estas tendem a estabelecer-se - como a própria filosofia - como disciplinas próprias paralelamente a outras. Não menos irrealista foi a expectativa de que a auto-gestão colegial das universidades, só pela acção de uma participação funcionalmente organizada dos grupos intervenientes, alcançaria uma dinamização e uma capacidade de acção políticas - sobretudo quando se sabia que a reforma teria de ser conseguida por via administrativa, contra a vontade dos professores.

Mas se nem mesmo à luz destas premissas se pode salvar a coesão interna da universidade, não seremos nós então forçados a reconhecer que esta instituição pode perfeitamente viver sem aquela idéia que um dia teve de si c a que tão fortemente se apegou?

\section{IV}

A teoria sociológica dos sistemas assume, já na escolha dos seus conceitos fundamentais, uma posição apriorística: pretende que todos os campos de acção social abaixo do nivel das orientações normativas devem a sua coesão à acção de mecanismos de controlo valorativamcntc neutros, como o dinheiro ou o poder administrativo. Para a teoria dos sistemas, a força integradora de idéias e instituições insere-e aprioristicamente na superestrutura mais ou menos funcional de um substrato de fluxos de acção c comunicação, sistematicamente coordenados c podendo prescindir de normas. Considero precipitada esta posição apriorística puramente metodológica. As normas e as orientações valorativas inserem-se sempre em contextos de vida prática, c por mais diferenciados que estes sejam, eles são a totalidade de fundo, e reabsorvem por isso todos os processos de diferenciação no amplexo da sua totalização.

A actividade científica continua, até hoje, a desenvolver-se no âmbito de um sistema de instituições com funções múltiplas e convergentes em escolas superiores científicas que de modo nenhum nasceram do horizonte do "mundo da vida" como as empresas capitalistas ou os organismos internacionais. Estamos ainda para saber se os grandes pojectos e a investigação fundamental, deslocados para fora da universidade, serão capazes de se libertar totalmente do processo generativo da ciência organizada no âmbito dessas universidades, se essas formas de investigação 
conseguirão andar por si próprias, ou se manterão um estatuto parasitário. Contra a sobregeneralização da teoria dos sistemas fala desde logo a experiência que Schelsky refere nos seguintes termos: "O que há de único na história institucional da universidade moderna é o facto de neste caso a diferenciação de funções se processar adentro da mesma instituição, e assim se não verificarem praticamente perdas funcionais devido à entrega de tarefas a outras organizações. Pelo contrário, pode até falar-se de um enriquecimento funcional, ou pelo menos de um aumento da importância e de um alargamento do âmbito das funções da universidade na sua evolução ao longo dos últimos cem anos".

Também Talcott Parsons, no seu livro ainda hoje determinante para uma sociologia da universidade americana, parte muito simplesmente do princípio de que o sistema universitário preenche simultaneamente quatro funções: a função central (a) da investigação c da formação de novas gerações científicas acompanhadas de perto (b) a preparação para a carreira acadêmica (e a produção de saber tecnicamente aplicável), bem como (c) tarefas que se prendem com a cultura $\mathrm{cm}$ geral $\mathrm{c}(\mathrm{d})$ contributos para a criação de uma consciência cultural própria c para o processo de formação intelectual crítica. Parsons tem como horizonte de referência o sistema universitário americano, institucionalmente mais diferenciado, e atribui as três primeiras funções a diferentes instituições - graduate schools, Professional schools e colleges. Mas cada uma destas instituições é, cm si, tão diferenciada que se desdobra c reparte, com variações de ênfase, por todas as funções. Só a quarta função não tem uma instituição que especificamente a suporte: realiza-se através da actividade intelectual dos professores. Atentemos no facto de que Parsons integra nestas quatro funções duas coisas essenciais: não apenas o trabalho de esclarecimento e formação crítica, voltado para fora e dirigido ao espaço público, mas também a reflexão sobre o papel próprio das ciências e sôbre a relação entre as esferas de valor culturais da ciência, da moral e da arte. Teremos então de concluir que este catálogo de funções propõe, sob forma nova, precisamente aquilo que os reformadores prussianos, no seu tempo, tinham 
feito valer como "unidades": unidade de investigação e ensino, unidade de ciência e cultura geral, unidade de ciência e esclarecimento crítico (Aufklárimg) e unidades das ciências.

É um facto que esta última idéia perdeu muito da importância que tivera: a pluralidade abertamente diferenciada das disciplinas científicas não constitui já, cm si, um meio capaz de articular todas aquelas funções. Mas os processos de aprendizagem universitária não só mantêm a sua interacção como a economia e a administração, como também continuam em estreita ligação com as funções de reprodução do "mundo da vida". Para lá de prepararem para a carreira acadêmica, a prática que propiciam de uma forma de pensamento científico (isto é de uma atitude hipotética face a factos e normas) permite-lhes dar o seu contributo para o processo geral de socialização; para lá do saber especializado, contribuem para a formação crítica intelectual, com as suas leituras fundamentadas dos acontecimentos actuais c as sua tomadas de posição política objectivas; para lá da reflexão sobre métodos e fundamentos, contribuem, com as ciências humanas, para uma continuidade hermenêutica das tradições, e com as teorias da ciência, da moral e da arte c literatura para a formação de uma consciência própria das ciências no âmbito geral da cultura. E é ainda a forma universitária de organização dos processos de aprendizagem científicos que permite que as disciplinas especializadas, para além de preencherem estas diversas funções, simultaneamente se enraizem no "mundo da vida".

É certo que a diferenciação das disciplinas exige uma diferenciação igualmente maior no interior da universidade. Trata-se de um processo que ainda continua - por exemplo com a instalação de "Graduate Collegcs" (Escolas de pós-graduação), recomendada pelo Conselho para a Ciência. Diversas funções são assumidas por diferentes grupos de pessoas em diferentes lugares institucionais e com diversos pesos relativos. A consciência corporativa dilui-se assim na consciência intersubjectivamente partilhada de que uns fazem coisas diferentes dos outros, mas que, todos juntos, fazendo de uma ou outra forma trabalho científico, preenchem, não uma função, mas um feixe de funções convergentes. Apesar deste processo de actividade científica com divisão de trabalho, essas funções 
não deixam de se articular umas nas outras. Mas a interação convergente de funções não pode hoje ser fundamentada, como Schelsky queria, na força unificadora do modelo normativo da universidade alemã. Perguntamo-nos mesmo se isso seria desejável.

E certamente útil aproveitar a comemoração do sexto centenário da fundação de uma universidade para recordar a idéia da universidade e aquilo que dela ainda resta. Talvez isso contribua para consolidar o "esprit de corps", de uma maneira ou de outra enfraquecido, dos membros da universidade. Mas isto só acontecerá se esse trabalho de rememoração assumir a forma de uma análise científica, não se ficando meramente pelo cerimonial, como forma de compensar, com emoções dominguciras, o dia-a-dia tecnocrático da universidade. Mal andaria a universidade se a consciência de si como corpo assentasse $\mathrm{cm}$ qualquer coisa como um modelo normativo: as idéias, assim como vêm, assim se vão. $O$ curioso na velha idéia da universidade estava precisamente em que ela se pretendia assente sôbre algo de estabilizador - precisamente o próprio processo científico definitivamente diferenciado. Mas se hoje a ciência não serve já de âncora ideal, porque a pluralidade de disciplinas não comporta já uma força totalizante, seja ela a de uma ciência filosófica fundamental de âmbito universal ou apenas a de uma forma de rellcxão da crítica material da ciência, oriunda das próprias disciplinas - não sendo assim, qual será então o fundamento de uma consciência própria c integradora desta "corporação"?

A resposta encontramo-la já cm Schleicrmacher: "O princípio primeiro de todo o esforço voltado para o conhecimento é o da comunicação; e, dada a impossibilidade de produzir seja o que for, ainda que só para nós próprios, sem linguagem, a própria natureza formulou de forma inequívoca esse princípio. Por isso se terão de constituir a partir de puro impulso de conhecimento todas as relações necessárias para a sua realização funcional, e as diversas formas de comunicação e de interação entre as várias actividades". Apoio-me, sem sentimentalismos, nesta passagem das "Idéias soltas sobre as universidades de um ponto de vista alemão", de Schleicrmacher, porque acredito verdadeiramente que são as formas comunicativas da argumentação científica que afinal permitem dar coesão c unidade aos processos de aprendizagem universitária nas 
suas diversas funções. Scheleiermacher considera que é "uma ilusão oca pensar-se que um indivíduo que se dedica à actividade científica pode viver isolado com o seu trabalho e os seus projectos": por mais que pareça que ele trabalha isolado na biblioteca, à secretária ou no laboratório, os seus processos de aprendizagem inserem-se inevitavelmente numa comunidade comunicativa e pública dos investigadores. Como o projecto -de cooperação na procura da verdade remete para estas estruturas de uma argumentação pública, a verdade — ou, digamos, apenas a reputação alcançada na "Community of investigators"; - nunca se poderá transformar num mero factor de comando de um subsistema aüto-regulado. As disciplinas científicas constituiram-se $\mathrm{cm}$ espaços públicos internos a cada uma delas, e só adentro destas estruturas elas poderão manter a sua vitalidade. Esses espaços públicos internos surgem em conjunto e voltam a dispersar-se no programa de actividades públicas da universidade. $\mathrm{O}$ velho título do "professor ordinário público" lembra o caracter público das lições, dos seminários e da cooperação científica nos grupos de trabalho dos institutos associados. O que Humboldt dizia da convivência comunicativa entre professores c estudantes aplica-se, tanto à forma ideal do seminário, como à forma normal do trabalho científico: "se eles (os estudantes e os colegas mais novos) se não juntassem espontaneamente à sua volta, era o professor que deveria procurá-los para chegar mais perto do seu objectivo, através da união do elemento experimentado, mas por isso mesmo já mais unilateral e menos vivo, com os mais fracos e ainda ousadamente empenhados numa procura des comprometida em todas as direcções".

Posso assegurar-vos que este- princípio se confirma, tanto para a forma de funcionamento, mais rigidamente organizada, de um Instituto Max Planck, como num seminário de filosofia. Mesmo fora da universidade, os processos universitários de aprendizagem mantêm algo da sua forma universitária original. Todos eles vivem da força estimulante e produtiva de uma disputa discursiva que traz consigo a "nota promissória" do argumento surpreendente. As portas estão abertas, a cada momento pode surgir um novo rosto c uma idéia inesperada.

Não gostaria, no entanto, de repetir o erro de apresentar como exemplar a comunidade comunicativa dos investigadores. No conteúdo 
igualitário e universalista das suas formas de argumentação ganham expressão apenas as normas da actividade científica, e não as do todo social. Mas elas participam de forma marcante daquela racionalidade comunicativa através de cujas formas as sociedades modernas - isto é, nao cristalizadas e libertas de modelos dominantes - terão de ganhar consciência de si próprias.

Tradução de João Barreto Departamento de Estudos Alemães da Faculdade de Ciências Sociais e Humanas da Universidade Nova de Lisboa 